\title{
Ectoparasites and Endoparasites among Oreochormis Niloticus (tilapia)
}

\author{
EVA GLADYS B. BADAR \\ gladys_badar@yahoo.com \\ Liceo de Cagayan University
}

Date Submitted: February 26, 2007

Final Revision Accepted: June 3, 2007

\begin{abstract}
The study investigated the parasites affecting Oreochormis Niloticus (tilapia) from the Cagayan de Oro River. The study revealed that there were ten (10) species of parasites infecting the different organs of the fish samples, namely Protozoans: Oodinium pilluris (egg), Chilodonella sp., Coccidia sp.and,Cryptobia sp.; Nematodes: Capillaria sp., Procamallanus sp.,Spirocamallanus sp. and Camallanus sp.; Cestode: Hymenolypis nana; and Acanthocephala: Acanthocephalus sp. The skin, gills, and fins were the organs harboring most protozoan parasites. The internal parts most infected with the different parasites were the stomach and intestine of the fish. Two species of parasites, cestode and acanthocephalan, were found to harbor pigs as part of their life cycle. Among the three water sources, the highest incidence rate of infection with Protozoan, Nematode, Cestode, Acanthocephalan parasites was in Barangay Carmen. Aside from the piggeries put up along the riverbanks, Barangay Carmen also receives all the wastes coming from the upper parts of the Cagayan de Oro River, thus making the rate of infection high. Lowest incidence rate of infection with the parasites was in Barangay Consolacion. This is due to the salinity of the water. Most fish health problems occur because of environmental problems such as poor water quality and existence of parasites.
\end{abstract}

Key words - Ectoparasite, Endoparasite, Protozoa, Nematoda, Cestoda, Crustacea, Acanthocephala, Monogenean Digenea 


\section{INTRODUCTION}

Tilapia (Oreochormis niloticus) is considered as the second most popular cultured fish in the Philippines after milkfish. It provides Filipinos with animal protein of low price and of excellent flesh quality. Liao and Chen, as cited by Acac (1990), said that tilapia is no longer an African fish but an international fish. It is believed that in the future, it may also become the most important finfish in the world.

However, with the increasing popularity of tilapia as a source of food, its natural habitat, which includes rivers and lakes, is not entirely free from pathological organisms such as parasites. Parasites of fish are integral parts of aquatic ecosystems. Especially in water bodies with poor environmental conditions, they can exert a strong regulatory effect on population. Environmental stresses can depress host immunity. Fish become more susceptible to infections and these can become more severe, even fatal. Sick and dead fish become a source of disease for the consumers. It cannot be denied that once the fish become infected with parasites, it would become a health threat to those who consume them. Also, profits start to decline.

Some symptoms of parasitic infections to human are unusual gastrointestinal problems such as bloating, cramping, diarrhea or unusual bowel movements. What makes the diagnosis difficult is that the symptoms may occur many hours or days after the consumption of the fish. Also, many people might mistake the symptoms simply as a case of "stomach flu" or other short-lived stomach problem. Other infections that people should be aware of is fish poisoning. Typical symptoms are like an allergic reaction: skin flushing, headache, oral burning, cramps, nausea, diarrhea, and itching. Symptoms may occur 10-30 minutes after ingestion and may last 6-10 hours.

Parasitology in tilapia is neglected. People raise and consume the fish without the knowledge of the parasites' presence and the parasites' harmful effect on human health. Eating raw tilapia, which is a delicacy among Filipinos, could be dangerous since the parasites could cause serious diseases. Considering the harmful effects of the parasite on the fish and on the human health, the researcher conducted this study to find out the parasites present in tilapia from the different areas of Cagayan de Oro River. 


\section{OBJECTIVES OF THE STUDY}

This study aimed at identifying the parasites present in Oreochormis nilotiicus (tilapia) from the selected areas of the Cagayan de Oro River. The objectives are: (1) identify the ectoparasites and endoparasites found among fish sample according to organ and water source/station; (2) determine the incidence rate of infection with Protozoans, Nematodes,Cestodes,Crustaceans, Acanthocephalans, Monogeneans, and Digeneans according to the organs and source of tilapia; and (3) make morphological descriptions of the different parasites collected and identified from the fish samples.

\section{MATERIALS AND METHODS}

In determining and identifying the parasites present in tilapia from the Cagayan de Oro River, the experimental research design, based on the Southeast Asian fisheries Development Center (SEAFDEC) Handbook published by Lacierda and Pagador (1999), was used in the study. Ocular inspections of the Oro River and an interview with the fish catchers were conducted to assess the areas where the fish would be collected. After which, three sampling stations were selected. The stations, which covered the whole water vicinity of the three barangays, were Station 1 - Barangay Carmen, Station 2 - Barangay 13 (Isla de Oro), and Station 3 - Barangay Consolacion (see attached map). The detection, examination, and identification of the fish parasites were conducted at the Zoology Laboratory of Liceo de Cagayan University, Cagayan de Oro City.

Reagents and Materials The following chemicals were used in the study: alcohol-formalin-Acetic (AFA) - a mixture of $60 \mathrm{ml}$ formalin, $500 \mathrm{ml}$ 95\% ethyl alcohol, $40 \mathrm{ml}$ glacial acetic acid, and $400 \mathrm{ml}$ distilled water, 5\% glycerine alcohol - a mixture of $95 \mathrm{ml}$ 70\% ethyl alcohol, $55 \mathrm{ml}$ glycerin, 70\% methyl alcohol - a mixture of $70 \% \mathrm{ml}$ methyl alcohol and $30 \mathrm{ml}$ distilled water, Methanol, Giemsa stain, and Canada balsam.

The following materials were used: Aerator, Four big basins, Tray, Binocular electric microscope, Photomicrograph microscope, Scalpel, Dissecting needle, Forceps, Pointed scissors, Glass slides, Cover slips, Medicine dropper, and Petri dish.

\section{Sample Collection}

Ninety (90) live tilapia (Oreochormis niloticus) were randomly collected regardless of age, size, and sex from the three assigned stations in the Cagayan de Oro River. The sample collection was done three times at a two-week interval, 
Liceo Journal of Higher Education Research

which started from the second week of August to the second week of September 2005. For every sampling period, ten (10) fish were collected from each station. These were transferred separately to aerated big plastic cellophanes with their natural water to keep the fish alive. The samples were transported to the Zoology Laboratory and transferred to four separate big basins with an electrical aquarium device (air pump) to obtain maximum aeration and to keep the fish alive longer. Immediate and detailed parasitological examination of the fish samples was performed to avoid contamination.

\section{Experimental Procedure}

\section{A. Fish Parasite Detection and identification}

This procedure was based on the Fish Health Management Handbook of Southeast Asian Fisheries Development Center, Aquaculture Department (SEAFDEC/AQD). The fish samples were immobilized first by placing them in NSS (natural saline solution) for 3-5 minutes. The fish were kept wet at all times during the examination.

Examination of Skin and Eyes - Individual scrapings of mucus including under and corner of skin and eyes were done using the dull side of scalpel blade in an anterior and posterior direction. The mucus scrapings were spread thinly on a glass slide with physiological saline solution (NSS) using a dissecting needle. These were then examined under a binocular electric microscope, starting from low to high power objective $(10 \mathrm{X}, 40 \mathrm{X}$, and $100 \mathrm{X})$ for parasite identification. The identification was referred to and based on the SEAFDEC Handbook and Invertebrate Zoology books. The parasites were identified while still alive and not yet deformed. The parasites were stained on a glass slide. The glass slides were then mounted and covered with a cover slip for documentation.

Examination of Gills - The left and right gills were removed and placed in a petri dish with NSS. Gill scrapings were made by holding the gill with forceps and running it with a blunt needle along the filaments gently to prevent excess blood in the sample. The mucus was spread on a slide using a dissecting needle. Five (5) slides of mucus scrapings were prepared for each fish sample and examined under the microscope. The same method of identification and data gathering in number 1 was used. The identified parasites were then stained, mounted, and covered with a cover slip for documentation.

Examination of Flesh and Internal Organs - The visceral cavity was dissected carefully by making a slit, using a pair of sharp-pointed scissors, from the anal opening to beneath the heart. One side of the body wall was removed to expose the viscera. The entire digestive organ was removed by cutting the esophagus close to buccal cavity and the rectum right at the anus. The entire components were 
placed in a petri dish with NSS, and each component (liver, heart, and intestine) was separated. Contents of the intestine were scraped and spread in a slide. These were examined under the microscope. Fresh squash preparations of the heart and liver were made. A piece of tissue from the specimen ( $3 \mathrm{~mm}$ in diameter) was compressed between the slide and cover slip. Microscopic examinations were done. The flesh behind the head was sliced in a posterior direction by filleting. The fillets were spread with the skin downward. The flesh was squashed in a slide for examination under the microscope. The cranium was opened by making a horizontal incision beginning just above the eyes. The brain was removed and spread on a slide. All the parasites found in the different organs were identified and recorded. Blood samples were obtained from the experimental fish and were spread thinly on a slide for examination and identification of parasites under the microscope.

\section{B. Fixation, Staining, and Storage of Parasites}

All the parasites observed were fixed and stained for storage and documentation. Each of the parasites was subjected to different fixation, staining, and storage process.

Protozoan - the parasite samples were smeared and air dried. They were then fixed with methanol for one minute. After which, the samples were stained with Giemsa and mounted with Canada balsam.

Nematode - the samples were fixed with a hot glycerin alcohol and were mounted with Canada balsam.

Monogenean - the parasites were fixed in a hot water and transferred to cold alcohol-formalin-acetic acid (AFA) overnight. They were then mounted with Canada balsam.

Digenean - the parasites were cooled with alcohol-formalin-acetic acid (AFA) overnight in a refrigerator and were then stored with $70 \%$ ethyl alcohol and mounted with Canada balsam.

\section{Photomicrography of the Identified Parasites}

Photographs of the parasites were taken using a photomicrograph microscope for documentation, which served as evidence to support the authenticity of the study.

\section{Statistical Tool}

The weighted mean was used to show the incidence rate of infection among fish samples. 


\section{RESULTS AND DISCUSSION}

\section{Identification of Ectoparasites and Endoparasites}

A total of ninety (90) tilapia from Barangay Carmen, Barangay Isla de Oro, and Barangay Consolacion were subjected to parasitological examinations using the direct microscopic technique and different staining methods published in the SEAFDEC Handbook. The parasites that were found on the external surface (ectoparasites) and in the internal parts (endoparasites) of the host fish were identified and recorded. Table 1 show that there were ten (10) species of parasites infecting the different organs of fish samples collected from the water vicinity of Barangay Carmen, Barangay Isla de Oro, and Barangay Consolacion. There were four species of Protozoans observed. Oodinium pilluris (egg) and Chilodonella $s p$., which were ectoparasitic, infected the skin, fins, and gills, which are major respiratory organs for young fish. The infection may suppress respiratory functions and cause fish suffocation. On the other hand, Coccidia sp. and Cryptobia $s p$. which are endoparasitic, affected the stomach and intestine of tilapia.

Furthermore, three species of Nematodes were observed. Capillaria sp. and Procamallanus sp., both endoparasitic, were found infecting the intestine and stomach, while Spirocamallanus sp., found to be both ectoparasitic and endoparasitic, infected the skin, fins, and gills. They burrowed the intestinal wall and encyst in flesh and liver tissues of the host fish. Cestode had only one speciesthe Hymenolypis nana, a flattened and tapelike worm- infesting the intestine of the fish samples. Acanthocephalus sp. of Class Acanthocephala, which is a spiny headed worm, infested also the intestine of the fish samples. All the fish samples from the three different water sources were free of Crustacean, Monogenean, and Digenean parasites. The specificity of parasite to host explains this. Organs of Oreochormis niloticus (tilapia) might not be their intermediate or final host to complete their life cycle. It might not be the kind of fish that nourishes them.

In terms of source, the Oodinium pilluris and Chilodonella sp. were observed in the fish samples collected from the three Barangays. Coccidia sp. was present only in fish from Barangay Carmen and Barangay Isla de Oro, while Cryptobia sp. was present in fish coming from Barangay Carmen and Barangay Consolacion. The Capillaria sp. was common among all fish samples. Camallanus sp. was observed in Barangay Consolacion and Isla de Oro; Spiracamallanus sp.and Acanthocephalus sp., in Barangay Carmen and Barangay Isla de Oro; Procamallanus sp. in Barangay Consolacion and Carmen; and Hymenolypis nana, in Barangay Carmen. It might be the salinity of the water, other physico-chemical factors of the water, and the host specificity of the parasites that affected the diversity of the parasites. 
Table 1. Type of parasites found among Oreochormis niloticus (Tilapia) according to source and organ

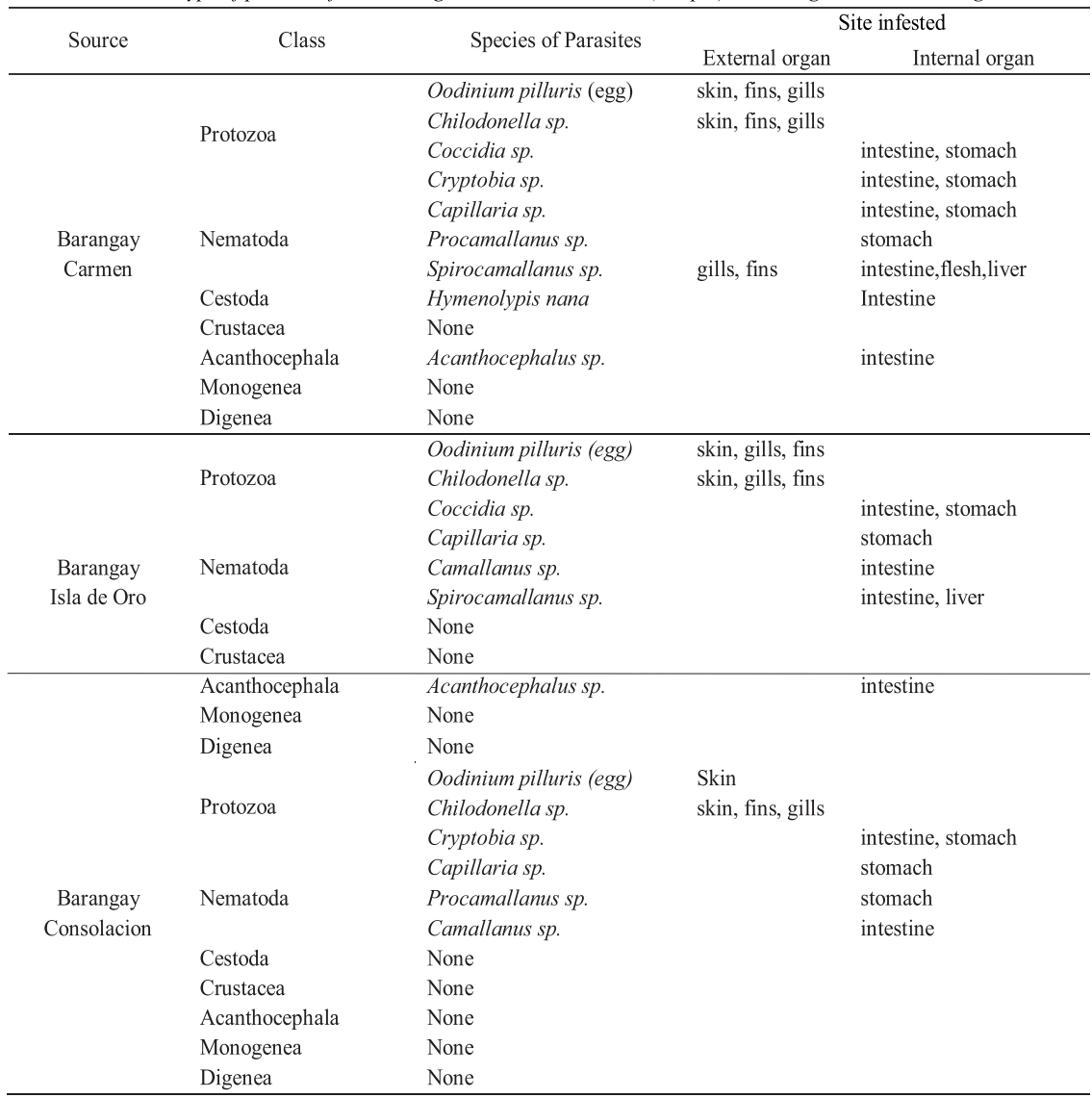

Table 2. Number of tilapia affected with protozoan parasites according to organ and source

\begin{tabular}{cccccccccc}
\hline Source & \multicolumn{7}{c}{ Fish organs infected with protozoans } \\
Table & Skin & Fins & Eyes & Gills & Liver & Stomach & Flesh & Intestine & Mean 2 \\
\hline $\begin{array}{c}\text { Barangay } \\
\text { Carmen }\end{array}$ & 93.3 & 86.6 & 0 & 100 & 0 & 93.3 & 0 & 100 & 59.15 \\
$\begin{array}{c}\text { Barangay } \\
\text { Isla de Oro }\end{array}$ & 83.3 & 73.3 & 0 & 66.6 & 0 & 67 & 0 & 76.6 & 45.85 \\
$\begin{array}{c}\text { Barangay } \\
\text { Consolacion }\end{array}$ & 60 & 70 & 0 & 83.3 & 0 & 63.3 & 0 & 53.3 & 41.23 \\
Mean & 78.86 & 76.63 & 0 & 83.3 & 0 & 74.53 & 0 & 76.63 & \\
\hline
\end{tabular}


The Protozoans infestation was widely distributed in most organs of the fish. However, the eyes, liver and flesh of the fish were free of the infection. The highest incidence rate of infection was on the gills (83.3\%). The infection on the skin $(78.86 \%)$ and fins $(76.63 \%)$ were also very high. These organs were infected with the protozoan ectoparasites, the Oodinium pilluris and Chilodonella sp. (see Table 1). According to Prescott (1997), the favorite sites of attack of Oodinium pilluris are the gills, skin, and fins of the fish. The most observed sign of the attack is panting. This parasite eats into the cells of the epithelial layer of the sensitive tissue and destroys them in the process. After the parasite has matured, it falls off the fish and, within the space of one day, finds another fish to infect causing heavy mortalities of the fish. Chilodonella sp., on the other hand, causes infected fish to secrete excessive mucus. Infected fish may flash and show similar signs of irritation. Many fish die when the infestation gets severe.

Of the fish sampled, $76.63 \%$ were also infected with the protozoans in the intestine and $74.53 \%$ were infected in the stomach. The organs were infected with Coccidia sp. and Cryptobia sp. (see Table 1). Fish affected with these parasites become thin, lethargic, and develop dark skin pigmentation. These parasites will not harm human because they are host specific. Their intermediate hosts are cattle, sheep, goats, swine rabbit, and dog (Floyd and Klinger, 2001). Therefore, internal organs should not be fed raw to animals, especially to pet animals. In terms of the source area, the data reveal that the highest incidence rate of infection with protozoan parasites was in Barangay Carmen (59.15\%). The rate of infection was 45.85\% in Barangay Isla de Oro and $41.23 \%$ in Barangay Consolacion. Barangay Consolacion, which had the lowest rate of infection, is close to the sea, thus the salinity of the water is high. According to Ronquillo and Borja (1975), the appearance of parasites is first noted when the salinity is low.

Table 3 reveals that the internal organs of the fish had a higher rate of infection than the external organs. The highest incidence rate of infection was in the stomach $(83.33 \%)$. The intestine also had a high rate of infection (75.53\%). The presence of the parasite in the flesh, however, was examined. As also shown, the fish were infested with Capillaria sp., Procamallanus sp., Spirocamallanus sp. , and Camallanus sp. (see Table 1). According to Floyd and Klinger (1997), heavy infestations of Capillaria are associated with debilitated fish. Infected fish may appear unsuitable for retail sales. The Camallanus sp., which is present in the intestine, flesh and liver of tilapia, develops with the aid of an intermediate and a carrier host (Bajao et al., 2002). The larvae are passed into the water with the feces of fish thus eaten by crustaceans, which, in turn, are eaten by the young fish in which the parasites do not proceed with development. By eating the fish, the final host including human, becomes infected with the parasite. It affects the stomach and intestine 
of the fish, resulting to the discoloration of the body surface. In human, its symptoms are similar to malaria. The early acute infection can be fatal. In this phase, parasites invade most organs of the body with irreversible damage to the heart and intestine. The patient becomes progressively weaker and may die from heart failure. Therefore, undercooked fish should not be eaten.

Table 3. Number of tilapia affected with nematode parasites according to organ and source

\begin{tabular}{|c|c|c|c|c|c|c|c|c|c|}
\hline \multirow[t]{2}{*}{ Source } & \multicolumn{8}{|c|}{ Fish organs infected with nematodes } & \multirow[b]{2}{*}{ Mean } \\
\hline & Skin & Fins & Eyes & Gills & Liver & Stomach & Flesh & Intestine & \\
\hline & $\%$ & $\%$ & $\%$ & $\%$ & $\%$ & $\%$ & $\%$ & $\%$ & \\
\hline $\begin{array}{c}\text { Barangay } \\
\text { Carmen }\end{array}$ & 0 & 53.3 & 0 & 40 & 26.6 & 100 & 30 & 90 & 42.48 \\
\hline $\begin{array}{l}\text { Barangay } \\
\text { Isla de Oro }\end{array}$ & 0 & 0 & 0 & 0 & 20 & 50 & 0 & 70 & 45.85 \\
\hline $\begin{array}{l}\text { Barangay } \\
\text { Consolacion }\end{array}$ & 0 & 0 & 0 & 0 & 0 & 100 & 0 & 66.6 & 41.23 \\
\hline Mean & 0 & 17.76 & 0 & 13.33 & 15.53 & 83.33 & 10 & 75.53 & \\
\hline
\end{tabular}

External parts of the fish, such as the fins (17.76\%) and gills (13.33\%), were also infected with nematodes, but of minimal incidence. In terms of the source area, the fish from Barangay Carmen (42.48\%) was the most infected with Nematode. Fish from Barangay Isla de Oro (17.5\%) and Barangay Consolacion (20.82\%) had very low rate of infection.

Table 4. Number of tilapia affected with cestode parasites according to organ and source

\begin{tabular}{|c|c|c|c|c|c|c|c|c|c|}
\hline \multirow[t]{2}{*}{ Source } & \multicolumn{8}{|c|}{ Fish organs infected with cestodes } & \multirow[b]{2}{*}{ Mean } \\
\hline & Skin & Fins & Eyes & Gills & Liver & Stomach & Flesh & Intestine & \\
\hline & $\%$ & $\%$ & $\%$ & $\%$ & $\%$ & $\%$ & $\%$ & $\%$ & \\
\hline Barangay & 0 & 0 & 0 & 0 & 0 & 0 & 0 & 60 & 7.5 \\
\hline \multicolumn{8}{|c|}{$\mathrm{B}$ : Ectoparasites and Endoparasites among Oreochormis Niloticus (tilapia) } & \multicolumn{2}{|r|}{ E.B. Badar } \\
\hline Isla de Oro & $u$ & $u$ & $u$ & u & u & u & u & $u$ & $u$ \\
\hline $\begin{array}{c}\text { Barangay } \\
\text { Consolacion }\end{array}$ & 0 & 0 & 0 & 0 & 0 & 0 & 0 & 0 & 0 \\
\hline Mean & 0 & 0 & 0 & 0 & 0 & 0 & 0 & 20 & \\
\hline
\end{tabular}

The only Cestode parasite that infested the fish was the Hymenolypis nana (see table 1), which is a flattened and tapelike hermaphroditic worm that is intestinal in human and other animals. As observed, it minimally infected only the intestines of the fish collected from Barangay Carmen. Other organs were not infected. According to Prescott (2001), intestinal cestodiasis, in which the mature worm lives in the intestine, produces eggs that are evacuated in the feces and develops further in human host and in other animal hosts such as cow and pig. It is possibly the most common cestode found in humans, affecting chiefly children. Symptoms of intestinal cestodiasis include abdominal pain that may be relieved by eating 
Liceo Journal of Higher Education Research

and that may be associated with distention, flatulence, nausea, or even more severe health problems. Only the fish in Barangay Carmen were infected with the parasite. The piggery, which animal wastes contaminated the water, might be one of the causes of the infestation.

Table 5. Number of tilapia affected with acanthocephalan parasites according to organ and source

\begin{tabular}{|c|c|c|c|c|c|c|c|c|c|}
\hline \multirow[t]{2}{*}{ Source } & \multicolumn{8}{|c|}{ Fish organs infected with acanthocephelia } & \multirow[b]{2}{*}{ Mean } \\
\hline & Skin & Fins & Eyes & Gills & Liver & Stomach & Flesh & Intestine & \\
\hline & $\%$ & $\%$ & $\%$ & $\%$ & $\%$ & $\%$ & $\%$ & $\%$ & \\
\hline Barangay & & & & & & & & & \\
\hline Carmen & 0 & 0 & 0 & 0 & 0 & 0 & 0 & 50 & 6.25 \\
\hline Barangay & & & & & & & & & \\
\hline $\begin{array}{c}\text { Isla de Oro } \\
\text { Barangay }\end{array}$ & 0 & 0 & 0 & 0 & 0 & 0 & 0 & 33.33 & 4.16 \\
\hline Consolacion & 0 & 0 & 0 & 0 & 0 & 0 & 0 & 0 & 0 \\
\hline Mean & 0 & 0 & 0 & 0 & 0 & 0 & 0 & 27.77 & \\
\hline
\end{tabular}

The same with the Cestode, only the intestine (27.77\%) of the fish was infected with Acanthocephalus sp. The infection was observed among the fish from Barangay Carmen (6.25\%) and Barangay Isla de Oro (4.16\%). According to Roberts (2000), Acanthocephalans are cosmopolitan parasites of pigs. When eggs are eaten by grubs (larvae of the beetle family Scarabaeidae), they hatch in the midgut within an hour. Pigs are infected by eating grubs or the adult beetles.

Table 6. Number of tilapia affected with crustacean parasites according to organ and source

\begin{tabular}{cccccccccc}
\hline Source & \multicolumn{8}{c}{ Fish organs infected with crustacia } & Mean \\
\hline & $\begin{array}{c}\text { Skin } \\
\%\end{array}$ & $\begin{array}{c}\text { Fins } \\
\%\end{array}$ & $\begin{array}{c}\text { Eyes } \\
\%\end{array}$ & $\begin{array}{c}\text { Gills } \\
\%\end{array}$ & $\begin{array}{c}\text { Liver } \\
\%\end{array}$ & $\begin{array}{c}\text { Stomach } \\
\%\end{array}$ & $\begin{array}{c}\text { Flesh } \\
\%\end{array}$ & $\begin{array}{c}\text { Intestine } \\
\%\end{array}$ & M \\
$\begin{array}{c}\text { Barangay } \\
\text { Carmen }\end{array}$ & 0 & 0 & 0 & 0 & 0 & 0 & 0 & 0 & 0 \\
$\begin{array}{c}\text { Barangay } \\
\text { Isla de Oro }\end{array}$ & 0 & 0 & 0 & 0 & 0 & 0 & 0 & 0 & 0 \\
$\begin{array}{c}\text { Barangay } \\
\text { Consolacion }\end{array}$ & 0 & 0 & 0 & 0 & 0 & 0 & 0 & 0 & 0 \\
\%Mean & 0 & 0 & 0 & 0 & 0 & 0 & 0 & 0 &
\end{tabular}

Table 7. Number of tilapia affected with monogenean parasites according to organ and source

\begin{tabular}{|c|c|c|c|c|c|c|c|c|c|}
\hline \multirow[t]{2}{*}{ Source } & \multicolumn{8}{|c|}{ Fish organs infected with monogenea } & \multirow[b]{2}{*}{ Mean } \\
\hline & Skin & Fins & Eyes & Gills & Liver & Stomach & Flesh & Intestine & \\
\hline & $\%$ & $\%$ & $\%$ & $\%$ & $\%$ & $\%$ & $\%$ & $\%$ & \\
\hline Barangay & & & & & & & & & \\
\hline Carmen & 0 & 0 & 0 & 0 & 0 & 0 & 0 & 0 & 0 \\
\hline Barangay & & & & & & & & & \\
\hline $\begin{array}{c}\text { Isla de Oro } \\
\text { Barangay }\end{array}$ & 0 & 0 & 0 & 0 & 0 & 0 & 0 & 0 & 0 \\
\hline Consolacion & 0 & 0 & 0 & 0 & 0 & 0 & 0 & 0 & 0 \\
\hline$\%$ Mean & 0 & 0 & 0 & 0 & 0 & 0 & 0 & & \\
\hline
\end{tabular}


Table 8. Number of tilapia affected with digenean parasites according to organ and source

\begin{tabular}{ccccccccc}
\hline \multicolumn{7}{c}{ Fish organs infected with digenia } \\
Skin & Fins & Eyes & Gills & Liver & Stomach & Flesh & Intestine & Mean \\
\hline$\%$ & $\%$ & $\%$ & $\%$ & $\%$ & $\%$ & $\%$ & $\%$ & 0 \\
0 & 0 & 0 & 0 & 0 & 0 & 0 & 0 & 0 \\
0 & 0 & 0 & 0 & 0 & 0 & 0 & 0 & 0 \\
0 & 0 & 0 & 0 & 0 & 0 & 0 & 0 & 0 \\
\hline
\end{tabular}

Tables 6, 7, and 8 shows that Crustacean, Monogenean, and Digenean parasites did not infect the fish collected from Barangay Carmen, Barangay Isla de Oro, and Barangay Consolacion. It might be that tilapia is not a host for their life cycle, or their intermediate hosts are absent in the vicinity, thus they cannot be developed. This could also be attributed to the physic- chemical factors of the water.

\section{Morphological Descriptions of the Parasites}

The parasites were identified while still alive to avoid the deformation stage. The photographs of these parasites, which are presented in this chapter, were taken using a photomicrograph microscope.

\section{PROTOZOA}

Oodinium pilluris

This protozoan parasite (eggs) has an ovular shape of varied sizes. It can measure, in some instances, more than 100 microns though more typical sizes are 50-70 microns. The observed parasite is both in free swimming flagellated stage and in parasitic stage when attached to the fish. The organism contains a form of chlorophyll. This gives the parasite its typical gold or rust color, and also enables it to obtain food as do plants by the process known as photosynthesis. However, when in the parasitic form, almost all of its nourishment is obtained at the expense of the host, and this causes tremendous damage that leads to death once the fish is heavily parasitized.

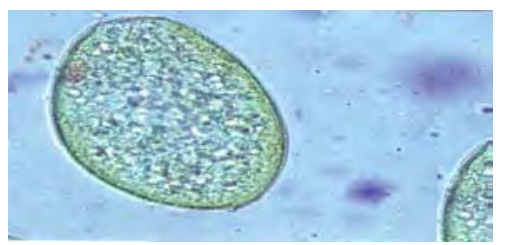

Plate1. A Photomicrograph of Oodinium pilluris in the Skin Mucous (1000X) 


\section{Chilodonella sp.}

Cholodonella sp. is a ciliated protozoan (see plate 2). It is a large, heart-shaped ciliate $(6$ to $80 \mathrm{~m}$ ) with bands of cilia along the long axis of the organism. The organism is easily recognized at $100 \mathrm{X}$ magnification. It has an anterior mouth or cytostome. It has macronucleus at the posterior part of the body. It usually reaches $0.5-1 \mathrm{~mm}$ in diameter. The observed parasite is in trophic nourishment stage. Chilodonella is easily identified using a light microscope to examine scraping of skin mucus or gill filaments.

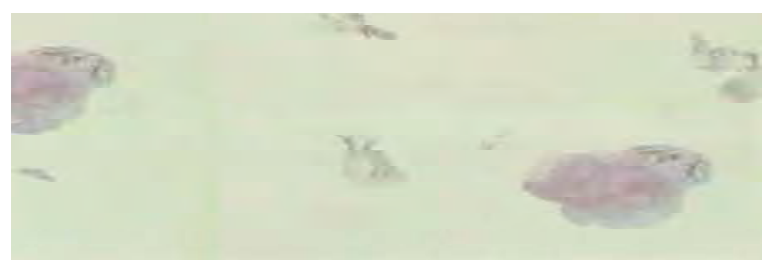

Plate 2. A Photomicrograph of Chilodonella sp. (Protozoan) (400X)

\section{Coccidia sp.}

Coccidia are intracellular parasites. The observed species are in the spore stage in which the cells are highly resistant to environmental conditions and can survive for long periods. Spores can be observed in squash preparations of the affected area (see Plate 3). The organisms are fusiform 10X1.5 um, no locomotory organelles, conoid at one end which serves to penetrate host cells, and with single nucleus. The species are found in the intestine. Inflammation and death of the tissue can occur, which can affect organ function.

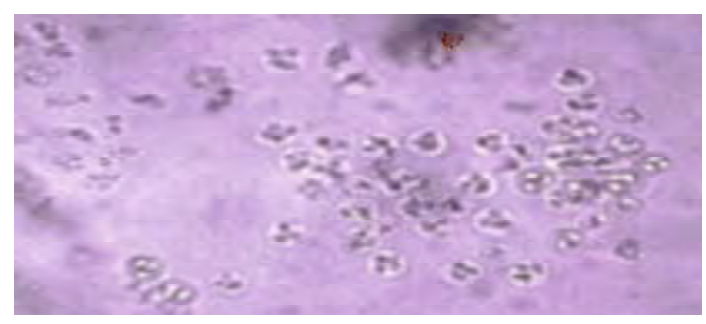

Plate 2. A Photomicrograph of Chilodonella sp. (Protozoan) (400X)

\section{Cryptobia sp.}

Cryptobia sp. is a flagellated ptotozoan common in cichlids. Cryptobia are more drop-shaped, with two flagella, one on each end. They wiggle in a dart-like manner. It is typically associated with granulomas in which the fish "walls off" the parasite. These parasites have been found primarily in the stomach, but may be present in other organs. 


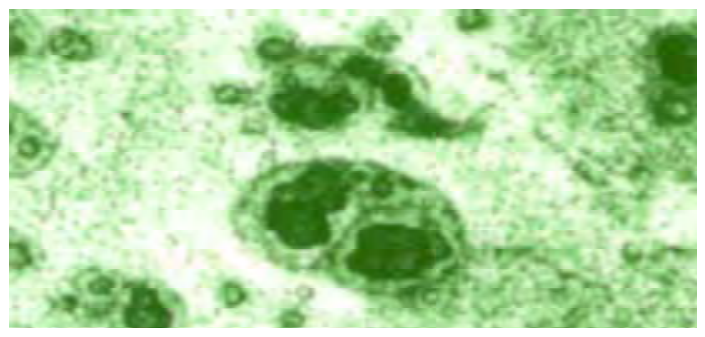

Plate 4. A photomicrograph of Cryptobia sp. Seen in a Wet Mount of Stomach

(Unstained Section - 400X)

\section{Capillaria sp.}

Capillaria is a large roundworm commonly found in the gut of the fish. Capillaria species are relatively transparent. Capillarid infection is relatively easy to diagnose when females containing the typical barrel-shaped eggs with a polar plug on each end (opercula) are present in the intestinal tract or the eggs alone are present. Heavy infestations are associated with debilitated fish, but a few worms per fish may be benign. This parasite is small; male measuring $2.3 \mathrm{~mm}$ to $3.2 \mathrm{~mm}$, and female measuring $2.5 \mathrm{~mm}$ to $4.3 \mathrm{~mm}$ long. The male has small caudal alae and a spineless sppicule sheath. The esophagus of the female is about half as long as the body.

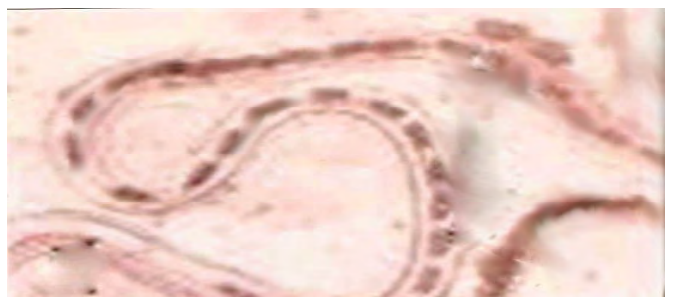

Plate 5. A Photomicrograph Showing Capillaria Female Showing Eggs

With Plug-like Structures at Each End (100X)

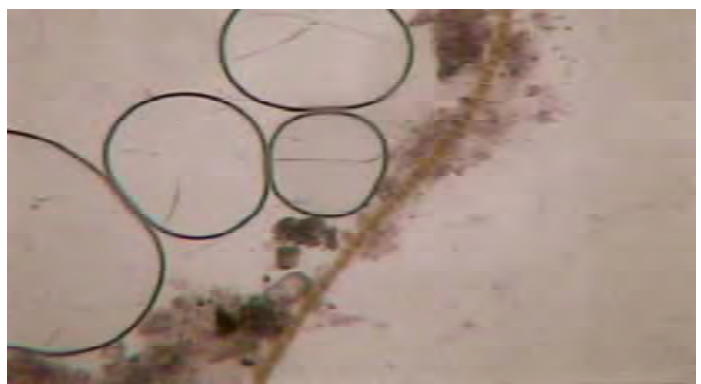

Plate 6. A Photomicrograph of Female Capillaria (40X) 


\section{Procamallanus sp.}

This worm is active and has cylindrical body. It is also transparent. Its body cuticle is finely striated. It is usually $15 \mathrm{~mm}$ to $25 \mathrm{~mm}$ long. Its mouth is enclosed in a buccal capsule. Its esophagus has also two parts, the glandular and muscular parts. There is a presence of nerve ring at the muscular esophagus at the midanterior portion. Tail is also curved ventrally.

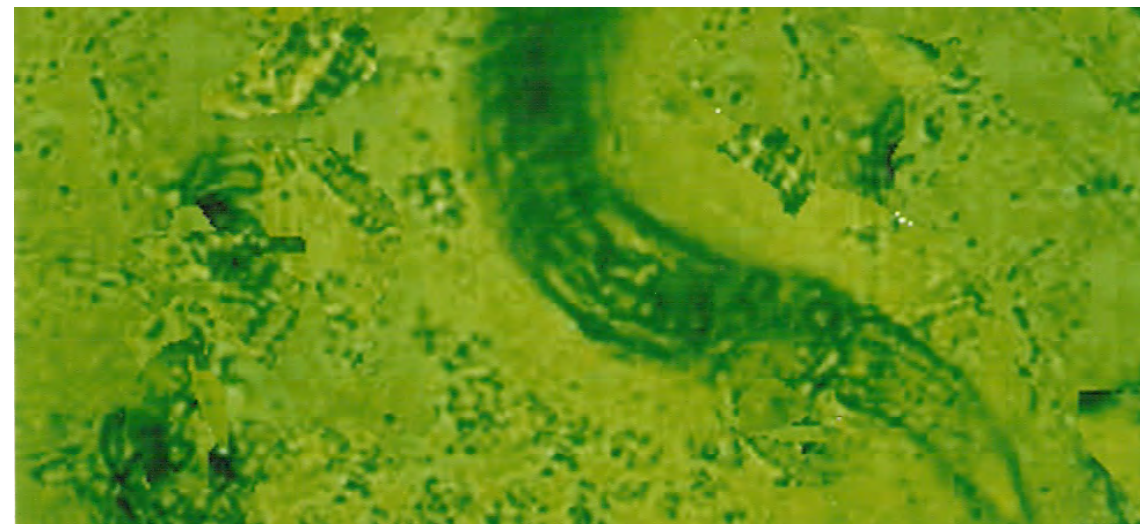

Plate 7. Photomicrograph of a Procamallanus sp. at 1000X (posterior portion)

\section{Spirocamallanus sp.}

The worm is transparent. The one recovered is an adult form that has slender and cylindrical body. Its body cuticle is finely striated and usually measures from $10 \mathrm{~mm}$ to $20 \mathrm{~mm}$ long. Its mouth is enclosed by a buccal capsule. Anterior is usually narrower than posterior. The parasite enters the human body when meat is inadequately cooked. It burrows the intestinal wall and encysts in muscular tissues.

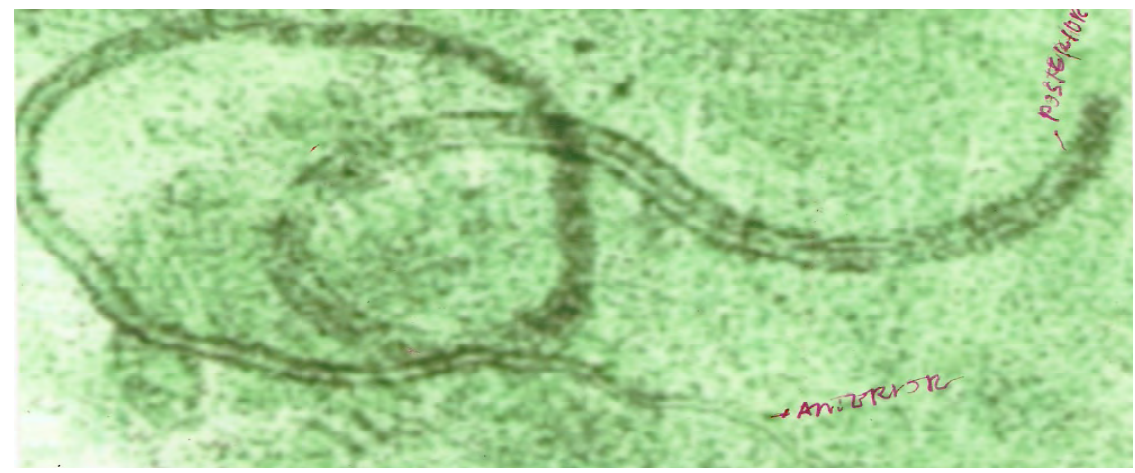

Plate 8. Photomicrograph of a Spirocamallanus Showing a Typical Nematode Shape (100X) 


\section{Camallanus sp.}

Camallanus $s p$. can be identified by its red color and its location which is further toward the posterior of the intestinal tract than other worm-like parasites (typically very near, and often protruding from the anus of the fish). The presence of a buccal capsule (mouth structure), which is divided into two lateral valves, gives the mouth a slit-like appearance.

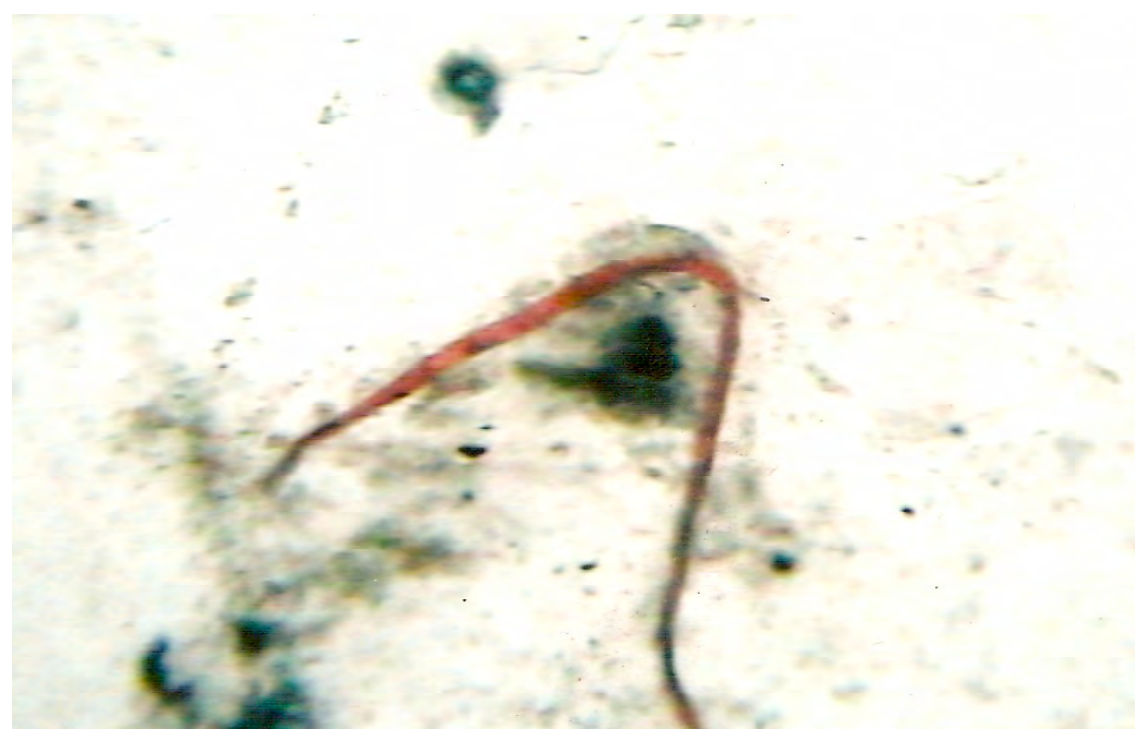

Plate 9. A Camallanus Nematode without Larvae Inside

\section{CESTODA \\ Hymenolypis nana}

The parasite, which is flattened and tapelike hermaphroditic worm that is intestinal parasite in human and other animals, produces larvae that can invade body tissues. It is also known as dwarf tapeworm, only a few $\mathrm{cm}$ long. It releases eggs that require no intermediate hosts. It has scolex with hooks and suckers and an armed rostellum. The body is termed as proglottids arranged in a linear series. 


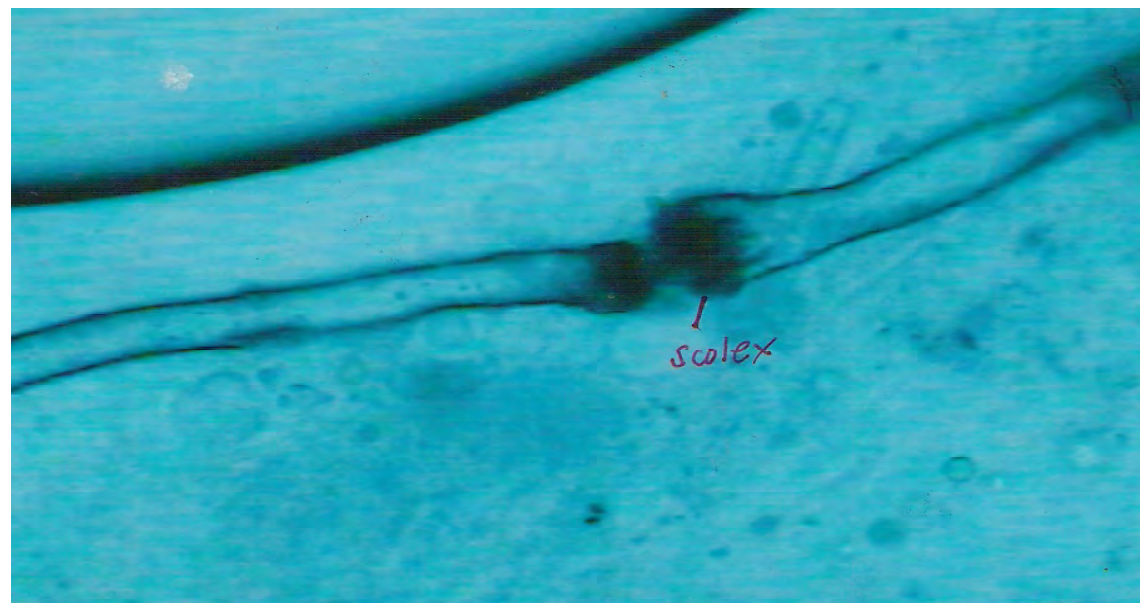

Plate 10. Adult Hymenolypis nana, Stained Mount Showing Scolex (40X)

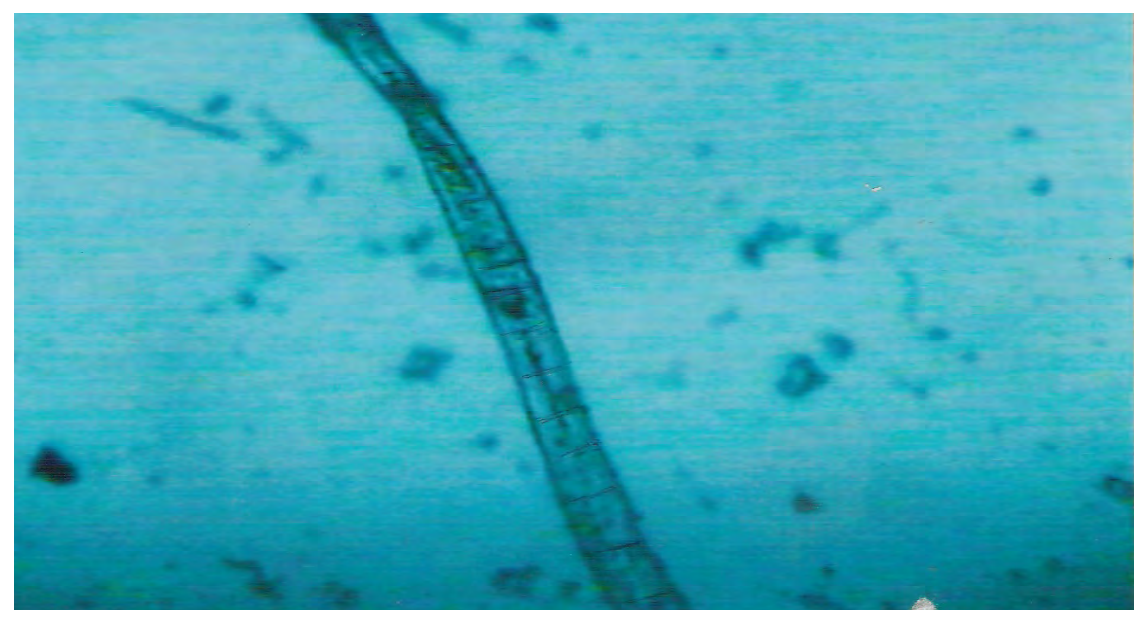

Plate 11. Body of Hymenolypis nana Showing Proglottids (40X)

\section{ACANTHOCEPHALA}

\section{Acanthocephalus sp.}

The spiny headed worms live in the intestine of vertebrates (pig) attached to the wall by a protrusible proboscis usually covered with recurved hooks. The adults vary in length from several $\mathrm{mm}$ to $\mathrm{cm}$. A layer of circular muscles and an inner layer of longitudinal muscles are between the epidermis. Because they are parasitic roundworms, they are considered closely related to nematodes. 


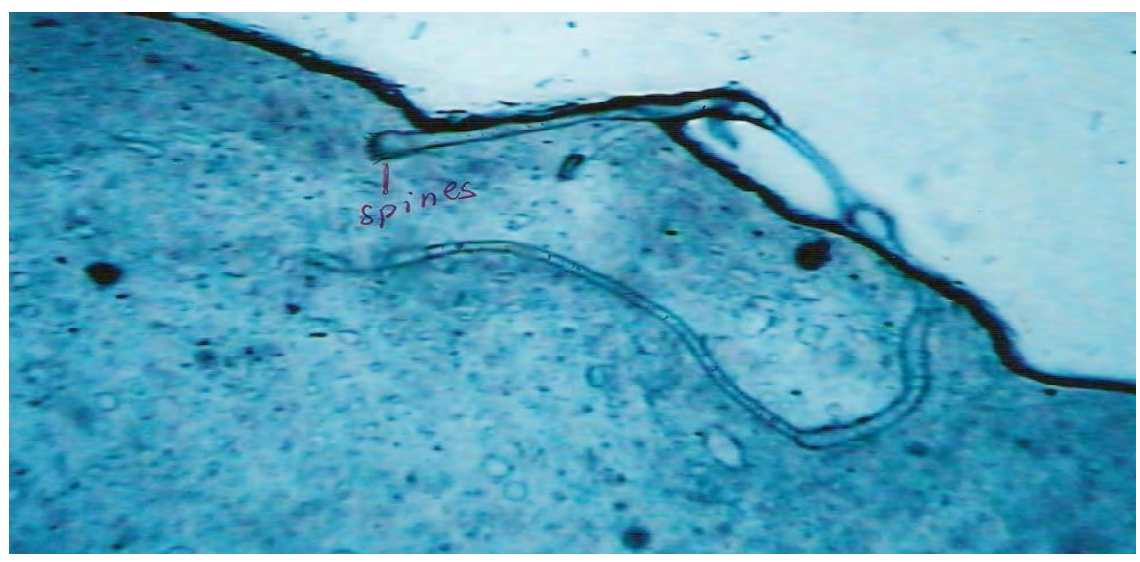

Plate 13. Acanthocephalus sp.'s spiny head with proboscis (400X)

\section{CONCLUSIONS}

There were ten species of parasites infecting the different organs of the fish samples, namely Protozoans: Oodinium pilluris (egg), Chilodonella sp., Coccidia sp., and Cryptobia sp.; Nematodes: Capillaria sp., Procamallanus sp., Spirocamallanus sp., and Camallanus sp.; Cestode: Hymenolypis nana; and Acanthocephala: Acanthocephalus sp. There was no infection with Crustacea, Monogenea, and Digenea in all fish samples from all water sources. The findings of the study revealed that the internal organs most infected with different parasites were the stomach and intestines of the fish. Thus the internal organs are not safe for human consumption. Also, they are not safe for domestic animals. The findings also showed less infection (10\%) in the flesh of the fish; therefore, the tilapias from the Oro River are very safe for consumption provided that the fish are thoroughly cleaned and cooked. The ectoparasitic species infected the skin, gills, and fins. The endoparasitic species infected the intestine and stomach, while only a few infected the flesh and liver. Protozoan infection was widely present in most organs except the eyes, liver, and flesh.

The highest incidence of infection was in the gills (83.33\%). There was also a high rate of infection on the skin $(78.86 \%)$ and fins $(76.63 \%)$. Intestines and stomach were also infected with protozoan parasites with an incidence rate of $76.63 \%$ and $75.53 \%$ respectively. The highest incidence rate of infection with Protozoan parasites was in Barangay Carmen (59.15\%). Protozoan infections were mostly in the internal organs. The highest incidence rate of infection was in the stomach $(83.33 \%)$. The intestine 
Liceo Journal of Higher Education Research

(75.53\%) also had a high incidence rate of infection. However, the external parts had minimal incidence rate of infection. The fish from Barangay Carmen (42.48\%) were infected with nematodes the most. The only Cestode observed was Hymenolypis nana, which infected the intestine (20\%) of the fish from Barangay Carmen. Other organs were not infected. Only one species of Acanthocephala was observed, the Acanthocepahlus sp. It infected only the intestine $(27.77 \%)$ of the fish coming from Barangay Carmen $(6.25 \%)$ and Barangay Isla de Oro (4.16\%). It was also found out that the water vicinity of Barangay Carmen had the most infected fish. The presence of piggery along the river banks and of the wastes coming from the upper part of the river highly polluted the river along Barangay Carmen. The salinity of the river along Barangay Consolacion has protected the fish from severe infestation with the parasites. The salinity of water is high because the river is estuarial.

\section{LITERATURE CITED}

Acac, P.L. (1990). Protozoan parasites of the gills, fins, and skin of tilapia at Pulangui River, Bukidnon. Undergraduate Thesis, Central Mindanao University, Musuan, Bukidnon.

Bajao, J. (2002). A comparative study of parasites present in selected freshwater fishes Cyprinus carpios (carp) and Oreochormis niloticus (tilapia) in Anibongan, Kitcharao, Agusan del Norte and marinewater fishes chanos chanos (bangus) and Mugil cephalus (gisaw) in Masao and Buenavista, Agusan del Norte. Undergraduate Thesis, Liceo de Cagayan University, Cagayan de Oro City.

Floyd R.F. and Klinger, R.E. (2001). Introduction to freshwater fish parasites. Retrieved June 20, 2005, from http//edis.ifas.ufl.edu/BODY_FA041.

Lacierda, E.C. \& Pagador, G. (1999). Fish health management: SEAFDEC Aquaculture Department, Tigbuan, Lolo.

Prescott S. (2000). Diseases of fish part 8: The Aquatic Animal Research Institute. Retrieved, June 22, 2005.

Roberts L. S. (2000). Foundations of parasitology (6th edition). Singapore: McGraw-Hill Book Company.

Ronquillo, I.A.(1975). Infestation of Chanos chanos (Forskal) by a parasite isopod. National Bargus Symposium: Manila 